\title{
Community acceptance of large-scale solar energy installations in developing countries: Evidence from Morocco
}

\author{
Susanne Hanger ${ }^{\mathrm{a}, \mathrm{b}, *}$, Nadejda Komendantova ${ }^{\mathrm{a}, \mathrm{b}}$, Boris Schinke ${ }^{\mathrm{c}}$, Driss Zejlid,e, \\ Ahmed Ihlal ${ }^{\mathrm{f}}$, Anthony Patt ${ }^{\mathrm{a}, \mathrm{b}}$ \\ a Swiss Federal Institute of Technology (ETH), Department of Environmental Systems Science, Climate Policy Group, Zürich, Switzerland \\ ${ }^{\mathrm{b}}$ International Institute for Applied Systems Analysis (IIASA), Laxenburg, Austria \\ c Germanwatch, Bonn, Germany \\ d Moroccan Society for the Development of Renewable Energy (SMADER), Casablanca, Morocco \\ e National School of Applied Sciences, Ibn Tofaïl University, Kenitra, Morocco \\ ${ }^{\mathrm{f}}$ Laboratoire Matériaux et Energies Renouvelables, Faculty of Sciences, University Ibn Zohr, Agadir, Morocco
}

\section{A R T I C L E I N F O}

\section{Article history:}

Received 28 July 2015

Received in revised form 25 January 2016

Accepted 28 January 2016

\section{Keywords:}

Climate change mitigation

Concentrated solar power

Community acceptance

Public acceptance

Middle East

North Africa

\begin{abstract}
A B S T R A C T
Renewable energy production is climbing the public agenda in many countries in the Middle East and North Africa (MENA region), for reasons of energy security, independence and local value creation. While technical and economic barriers are largely understood, in this paper we investigate the issue of community acceptance. In so doing, we explore the importance of relevant drivers of community acceptance such as level of expected socio-economic and environmental impacts, procedural and distributive justice, and trust. We conducted 232 face-to-face interviews with the local population in Ouarzazate in Morocco, the building site of a flagship project for concentrated solar power in the MENA region. We find that community acceptance is almost universal, particularly because solar power is perceived to be environmentally friendly. At the same time perceived level of knowledge about the project is very low, which is positively linked to the high level of acceptance. Our data suggest that there may be some social desirability bias distorting community acceptance; only long-term experience with the project will show whether hopes for job creation will be fulfilled and high levels of acceptance can be maintained.
\end{abstract}

(c) 2016 Published by Elsevier Ltd.

\section{Introduction}

Across the countries of the Middle East and North Africa (MENA region), national governments have set ambitious targets to obtain a substantial share of their energy mix from renewable energy sources, such as solar, as well as on-shore and off-shore wind. Many of these projects involve some degree of international cooperation, such as multi-lateral or donor financing, or energy trade. Several studies show evidence that technological capacities are already existing $[33,26]$. While the first set of pioneer installations are by now operating, several other large-scale projects are planned or are currently under construction. In Morocco, in the context of the ambitious Moroccan Solar Plan, several sites have been identified for the large-scale collection of solar power. At the national level large expectations are attached to these projects, with respect to energy security, climate change mitigation, self-reliance and

\footnotetext{
* Corresponding author at: ETH Zürich, Department of Environmental Systems Science, Climate Policy Group, Building CHN, Floor J, Office 72.1, Universitätstrasse 22, CH-8092 Zürich, Switzerland.

E-mail address: susanne.hanger@usys.ethz.ch (S. Hanger).
}

balance of payments, as well as a number of socio-economic factors along the renewables value chain [38]. The first of these sites to be developed is the Noor I concentrated solar power (CSP) plant in Ouarzazate, a flagship project for the entire MENA region. The successes and challenges associated with this unprecedented project in the region will be defining for the international support for future development of renewable energy technologies (RET) in the region.

Many potential barriers have been identified that may impede or slow down the introduction of renewable energy and the associated infrastructure for energy generation and transmission. A primary barrier to have been identified is project financing, given risks for both private and public investment that are associated not only with new technologies, but also for long-lived infrastructure in a region that is not necessarily viewed as the most politically stable [29]. A barrier that has frequently arisen in developed countries, but which remains under-researched in developing countries, is that of public acceptance and associated permitting. In European countries, for example, this has not only delayed the realization of many projects, but has also put entire projects in jeopardy. Indeed, the civil society sector has identified community awareness and acceptance as important bottle-neck for the successful implementation 
of large-scale renewable energy production in the MENA region (e.g., Refs. [30,38]).

One particularly important aspect for the successful implementation of renewable energy production is the acceptance by the communities in the direct vicinity of renewable power plants. In the academic and grey literature, local public resistance against infrastructure projects is known as the not-in-my-backyard (NIMBY) syndrome, which in turn is frequently used to refer to the broader term of community acceptance. These issues have been addressed mostly in the context of wind energy (e.g. Refs. [11,39,43,12,17,18] and transmission lines [5] in Europe and North America. For developing and emerging economies in general and the MENA countries in particular, there is only limited evidence on the role of public perception and community acceptance of renewables.

The literature shows how community acceptance is influenced by a number of factors, including expected costs and benefits, social, economic and environmental risks, trust and perceived fairness, distance to the proposed power plant and the regulatory context $[39,36]$. It is interesting to find out whether these independent variables are equally important for community acceptance in the context of MENA countries, in the light of a socio-cultural context that is significantly different from that of European and North American countries. These are, for example the much closer link between the state and religion, as well as patriarchal and authoritarian public and private institutions.

The aim of this paper is to identify whether and to what extent community acceptance is relevant in the Moroccan context, taking this as a country that is at the forefront of RET development in the MENA region, and to find out the main drivers for positive attitudes or resentments towards renewable energy installation in a community. The acceptance of CSP installations by local communities and their perceived benefit is key for the legitimization of these and similar endeavors. This research is thus relevant to unravel potential for future conflict and barriers to the long-term success of largescale renewable energy production not only in Morocco, but also in other MENA countries.

\section{Background}

\subsection{The role of CSP in MENA and Morocco}

Concentrated solar power (CSP) is a potentially attractive source of renewable electricity for load centers near arid regions [6,21]. Utilizing thermal storage, CSP plants can operate after the sun goes down. Pfenninger et al. [25] demonstrated that a network of CSP plants could supply baseload and load-following electricity, at levels of reliability comparable to fossil fuel or nuclear power plants, and at costs comparable to photovoltaic (PV) or offshore wind. Morocco has been identified as an ideal country for CSP development [27,34]. First, there is an opportunity for CSP to replace existing diesel generators, which are substantially more expensive to operate, to satisfy local needs. Second, the country is separate from load centers in Europe only by the Strait of Gibraltar, making exports through Spain an economic possibility. Third, Morocco lies to the west of most of Europe, meaning the time of peak solar energy capture corresponds well with late afternoon and evening peak load periods.

At the same time Morocco is the only North African country without any noteworthy fossil energy reserves. It must import almost all of its primary energy [7]. In 2008, imports accounted for $98 \%$ of national energy use and for 11 percent of GDP [14]. Against the background of rising energy demand and limited domestic fossil fuel reserves, the use and development of renewable energy technologies have become a major priority in the national energy strategy of Morocco [16]. By 2020, renewable energy is projected to account for $42 \%$ of the $14,580 \mathrm{MW}$ power capacity in Morocco. The total renewable energy production will be equally shared by solar, wind and hydro power. This includes the Moroccan Solar Plan, a 2000 MW solar power project launched on November 2, 2009. To aid its implementation Morocco launched a legal and regulatory framework for the energy sector. The renewable energy law, the law for the creation of the National Agency for the Promotion of Renewable Energy and Energy Efficiency (ADEREE) and a law of the Moroccan Agency for Solar Energy (MASEN), which is the prime contractor for the envisaged solar power projects [16]. According to its high direct normal irradiation (DNI) potential, Ouarzazate was chosen to host the first power plants foreseen in the Moroccan Solar Plan.

International investors and developers, such as the African Development Bank (AfDB), the World Bank (WB), the European Investment Bank (EIB) and others are supporting the Moroccan government by means of loans and grants. Therefore, the project is subject to strict environmental and social standards. Environmental and social impact assessments have been issued or commissioned by MASEN [22] the AfDB [2] as well as by the Saudi Arabian company ACWA heading the consortium [1]. The NGO Germanwatch and the Wuppertal Institute [38] initiated an even more comprehensive investigation on the impacts of the project on local livelihoods. They attest local stakeholders an overall positive attitude towards the project, with the main expectations and concerns being related to generating employment and local value creation, access to information and participation, as well as potential negative impacts due to competing water uses. They also reflect positively on MASEN's efforts to communicate with local stakeholders, and to channel benefits into the communities in the vicinity of Noor I through a Social Development Plan, which was set up to allocate and distribute the financial means, which resulted from the acquisition of land for the project from local communities. While in the context of the mentioned studies the focus was on key stakeholder groups, in this paper we investigate perceptions and attitudes of the general public and the resulting levels of acceptance.

\subsection{Drivers of public acceptance}

In the academic literature a variety of terms are used to describe acceptance issues. These terms are often used inconsistently or interchangeably although they refer to different notions. The vocabulary includes public perception (e.g., Refs. [28,17]), public acceptance (e.g., Refs. [43,10]), social acceptance (e.g., Ref. [41]), NIMBYism (e.g., Refs. [12,24]), willingness-to-pay/use [3,42], and public support [35,9]. Batel et al. [4] highlights that an agreement on how to measure acceptance is missing, and criticizes the resulting lack of comparability of concepts and results regarding public acceptance. We consider the term acceptance to include a range of potential attitudes towards RET that are other than active opposition, including apathy, passive acceptance, approval, and finally active support. In this study we do not investigate these distinctions in detail.

Acceptance can take place at different object levels, with respect to technology, infrastructure or applications; and at the same time in different arenas, such as political spheres, in markets, and in communities [39,32]. Our focus is at the nexus of infrastructure and communities, where we examine several factors that influence the level of acceptance. The first of these, positive and negative social and economic impacts of renewable power installations, is frequently mentioned as drivers for public acceptance (e.g., Refs. $[24,15])$. For example, two studies, one on Germany and another one on China, identified how perceptions of costs and benefits of RET can impact acceptance. By means of household surveys in three German case study areas (each addressing either a large PV 
installation, a biomass plant or wind turbines) Zöllner et al. [43] identify individual perceptions of costs and benefits as the strongest predictor for reported acceptance. In the Chinese context, Yuan et al. [41] include cost-benefit concerns in a case study of public acceptance of wind power, but found that only $15 \%$ of respondents considered this to be the most important benefit of developing wind energy. In the case of the MENA region and particularly in a socio-economically disadvantaged rural area, such as Ouarzazate, we assume that expected socio-economic benefits might play a major role in favor of the planned CSP plant.

Environmental impacts can also play a role. There is only slight documentation (e.g. Refs. $[12,24]$ ) of the effects of positive and negative environmental impacts being drivers of community acceptance, which leads us to believe that it is often implicitly assumed that renewable power is inherently environmentally beneficial and thus can be booked in favor of installing additional capacities. For a case study of Shandong, China, Yuan et al. [41] identified environmental benefits as the most salient advantages in the respondents view. We assume that in less developed regions socioeconomic issues are more salient than negative environmental impacts. However, given the decade long drought in the Ouarzazate region we expect water-related impacts to be of particular concern to the population. Also, the land requirements for utility-scale RET projects are substantial. Land is an important livelihood resource and thus a constraining factor especially in rural areas that depend very much on subsistence agriculture. The advantage across the MENA region is that desert areas provide ample land, which is free from competing uses and scarcely populated. Controversies about aesthetics or dedication to other purposes are thus less likely.

Related to the perceived economic risks and benefits, distributive justice or the distribution of socio-economic risks and benefits among different social groups may be a major concern among the population and may influence public perception of large-scale renewable installations [12]. Somewhat related as well is the issue of procedural justice. Firestone et al. [15] proposes a set of key principles of procedural justice, which are the ability to express opinions freely, to have a voice and to be heard, to fully participate in the process, to have access to adequate information, to be treated with respect, and to have an unbiased decision maker. Two of these are most often reflected in empirical studies: (1) The involvement of different (local) stakeholder groups and the consultation of the general public particularly in the siting phase $[36,43,45]$. (2) The accurate and accessible information provided to the population from early on in the planning phase of projects (e.g., Refs. $[20,43,24])$.

Likewise, trust is a crucial element that takes long to build and which is easy to lose [31]. Wolsink [37] identified trust as a crucial element when it comes to building social acceptance. In some cases trust was found to be closely linked to the origin of the developers and whether they are insiders or outsiders, i.e., whether they know the region well and see level with the local stakeholders and the general public [19,20,13]. For factors influencing acceptance of new technologies more broadly, Gupta et al. [47] found trust to be the second most explored factor after perceived risk.

Geographical factors can also play a role. NIMBY is often used as a shorthand term for local opposition, and used to explain local opposition as based on selfishness, irrationality or ignorance [8], but also refers to the fact that individuals who generally support RET might still be against concrete projects in their close vicinity $[12,24]$. Consequently NIMBY suggests that opposition/negative attitudes increase with decreasing distance of a residence to the location of the renewable power plant. This concept has suffered in popularity as other factors have been found to have additional or more explanatory power [12,35]. However, there might still be value in accounting for distance in different cultural contexts. For instance, Guo et al. [46] found for China that distance does indeed

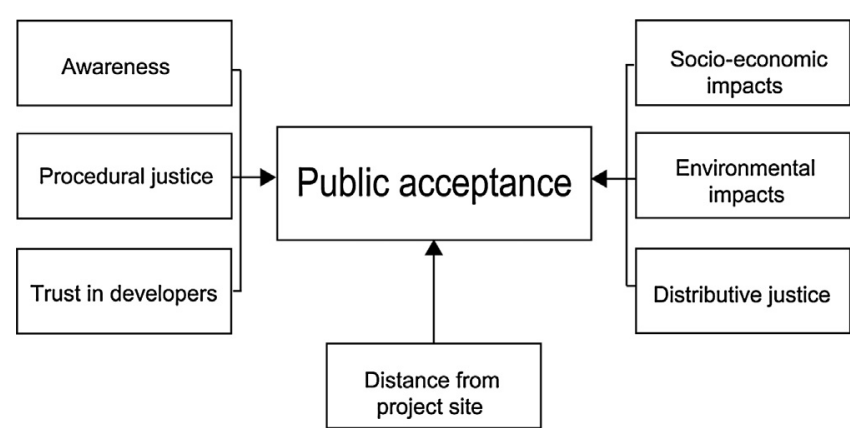

Fig. 1. Model of community acceptance. Source: own design. We hypothesize that community acceptance is positively influenced by (1) a varying level of information (awareness), (2) the extent of public involvement, (3) high levels of trust in developers and international investors, (4) expected positive socio-economic impacts, (5) expected positive environmental impacts, (6) expected distribution of positive impacts (equity) and (7) increasing distance of the respondents home from the project sight.

matter and while people do not appreciate wind parks in their back yard they would like to have it in their own county rather than elsewhere in China. Landscape aesthetics are, apart from the NIMBY argument, most frequently considered to be an important driver of public acceptance. Wolsink [36] using different European survey data on public acceptance from 1986 until 2002 identified visual evaluation to be the dominant factor for public acceptance issues. Negative impacts on landscape and visibility of energy generation and transmission infrastructure are also reported in Devine-Wright [12] and Petrova [24].

Most of these drivers have been identified in the context of countries in Europe and North America and were tested frequently for the acceptance of wind power on and off-shore and in a few cases also for solar power (e.g., Carlisle et al. [9] investigating public opinion on utility scale solar in California) and carbon capture and storage (Oltra et al. [23] eliciting lay perceptions through focus groups in Spain). In the context of developing countries and emerging economies in particular the academic focus so far has been on the private use of renewable technologies, while research on community acceptance of renewables has started to emerge only recently (e.g., $[41,40,44])$. There is little systematic research on factors influencing community acceptance. Moreover, due to the afore mentioned lack of clarity of similar concepts it is difficult to clearly identify differences between relevant drivers in different political and cultural contexts. Based on this literature it seems that the drivers investigated to be similar across different countries and development contexts across the globe.

\section{Method}

\subsection{Model of acceptance and independent variables}

We studied community acceptance for the Noor I solar project in Morocco using a household survey. In doing so, we started with a theoretical model of such acceptance, as a means of structuring questions on a household survey instrument. Fig. 1 provides a schematic of that model. The left hand variables in the figure refer to factors associated with the project development process. These include awareness and level of information, which previous findings would suggest to be relevant in the remote setting of the Noor I project and in a political culture of top-down planning and decision making. This can be seen as pertaining to the above described procedural justice driver. Procedural justice refers to information practices of developers as well as active participation of citizens in the planning and development process, while trust in developers includes trust in international institutions, since these 
played an important role in the financing of the project. The right hand variables are those associated with the anticipated project outcomes, surveyed in terms of risks and benefits. These are the socio-economic impacts, environmental impacts, and the expected distribution of benefits. A final variable is purely geographical, and is the distance of each survey respondent from the site.

\subsection{Survey design and pre-testing}

The questionnaire was designed to reflect our model of community acceptance. One section was dedicated to the dependent variable, one to each major driver we intended to test, where procedural and distributive justice were integrated with awareness and socio-economic impacts respectively. We added an additional section including miscellaneous questions for control purposes and considering other topics of interest such as attitude towards energy imports as well as a standard section collecting demographic and socio-economic context data.

The survey was developed in English with all partners involved and translated into Arabic by our partners at the University of Agadir. We had to limit the length of the questionnaire and were thus not able to include multiple-items per question for testing of validity and reliability by means of statistical techniques. However, the survey was pre-tested at the University of Agadir and critically discussed by the local interviewers, who had previously gained experience in conducting interviews in the Ouarzazate region through a separate ongoing research project [38]. The interviewers were multi-lingual and briefed how to adapt the questionnaire to Berber and Darija if necessary. After a first set of interviews we reflected each questionnaire item as to whether respondents were able to cope with it. Furthermore a set of questions to the interviewer about how well the respondents seemed to understand the questionnaire gave us some insight both on validity and reliability. Indeed, interviewers reported difficulties of understanding in several cases, we thus created respective control groups in the data in order to test whether these cases influenced the analysis. As this was not the case we decided not to drop these observations from the data set.

\subsection{Sampling}

We conducted face to face interviews with a sample of 232 people, in the period between the 8th and the 13th of March 2014. The survey targeted the population age 18 and older, living in a radius of $60 \mathrm{~km}$ of the construction site of the Noor I CSP plant. In order to test for the effect of distance on community acceptance we divided the area into three parts: people living less than 20, 40 and $60 \mathrm{~km}$ from the power plant.

Due to the absence of an adequate sampling frame such as population, phone or address register as well as for constraints of funding and time, we applied a multistage area sampling strategy using a combination of the most recent census data (2004) and Google Earth, and drew our sample in two steps. While a list of communes was freely available from a database of administrative areas (www. gadm.org), we were not able at the time to find a complete list of settlements or the respective shape files. Therefore we relied on the Google Earth Pro satellite imagery to identify settlements in the sample communes.

In the first sampling stage one urban and two rural communes were randomly selected from the list of communes within $20 \mathrm{~km}$, $40 \mathrm{~km}$ and $60 \mathrm{~km}$ of the Noor I CSP plant. Samples were drawn for the rural and the urban households independently to represent the proportion of rural and urban population in the region. This was within a $20 \mathrm{~km}$ radius about $84 \%$ urban and $16 \%$ rural, within the $40 \mathrm{~km}$ radius about $93 \%$ rural and $7 \%$ urban (or actually $100 \%$ rural, depending on the definition for urban settlement), and within a $60 \mathrm{~km}$ radius about $88 \%$ rural and $12 \%$ urban.

In the second sampling stage, for the rural communes selected in the first step, all settlements were identified based on Google Earth satellite images. From this list we drew a random sample. In the sample settlements the interviewers went from building to building to find respondents. Apart from the large cities, dwellings were often not built along roads or in any systematic layout that would facilitate a more systematic, randomized approach.

The urban communes selected were overlaid with a grid in Google Earth, the fields were numbered and a random sample was drawn. Again we refrained from a further digitization and yet another sampling stage as we did not have the capacity for an exante inventory and an on-the-go strategy was beyond our resources as well. Sampling specific households would also not have been feasible as we were able to visit each household only one time and the probability was high that we would not find the residents at home.

\section{Results}

\subsection{Sample profile}

We conducted 151 interviews in urban areas and 81 interviews in rural areas, reflecting the proportion between urban and rural population. The age distribution in our sample differs somewhat from the age distribution across the field work area as a whole, which is similar to Morocco based on data from the 2004 census: men and women aged 45 and older are slightly underrepresented. Young women under the age of 35 were more willing to participate in the survey than women over 35 , which may be linked to their education and better access to information (cf. Fig. 2). The median age of the respondents was 33 years (mean age 34 ). Based on the available data (five year age groups from 2004 census) we estimate that this reflects the median age of the region quite well.

The average response rates were $85 \%$ in rural areas and $50 \%$ in urban areas. Women were much more reluctant to talk to the interviewers which led to more male (149) respondents than female (83).

The level of education (Fig. 3) of our sample was higher than the average level of education of the region and even Morocco (Census 2004), most likely due to the large number of interviews in urban areas and larger number of male respondents aged 25-45, where level of education is traditionally higher than in rural areas or among women. The employment status reflects the vulnerable state of the area: $17 \%$ of our respondents were seeking employment, whereas the largest group was self-employed (35\%), i.e., most likely working in agriculture or small business. The fact that only four respondents worked for a civil society association, reflects their slight influence in the region.

\subsection{Key variable values}

Information on the self-reported community acceptance of the Noor I project was collected on a 5-point scale 1 being completely in favor and 5 completely against. Reported acceptance was very high, with most of the population (91\%) being either completely in favor or in favor of the project (Fig. 4). Qualitative interviews done by Germanwatch and the Wuppertal Institute [38] reveal that this can be attributed to MASEN's approach addressing the interest and needs of local communities in the neighborhood of the project. By recognizing the importance of local communities in successful CSP development, a high level of support was achieved in the Province of Ouarzazate, even among local communities who may be negatively affected or who are living in proximity to the project. 


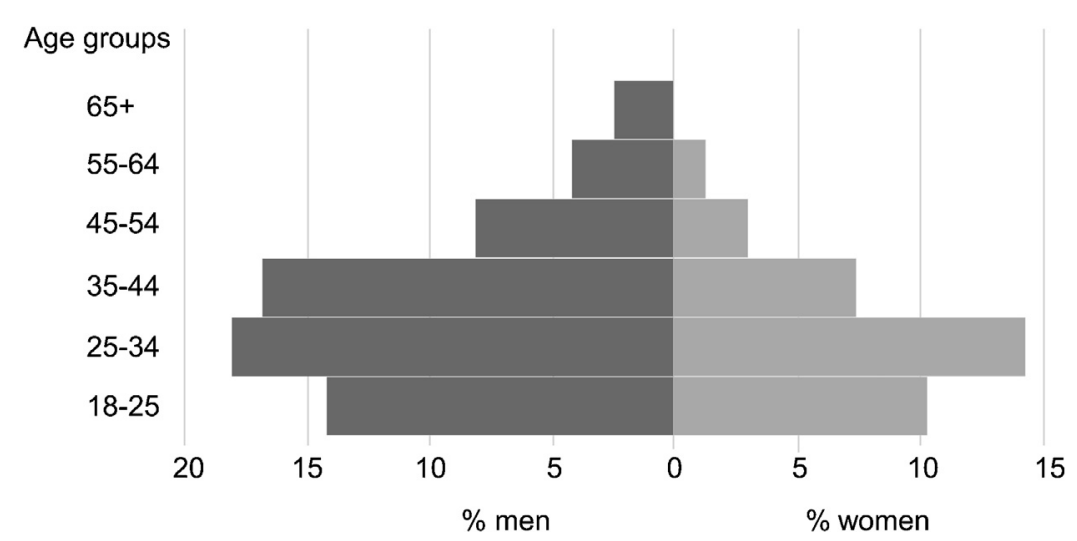

Fig. 2. Population pyramid of the sample.

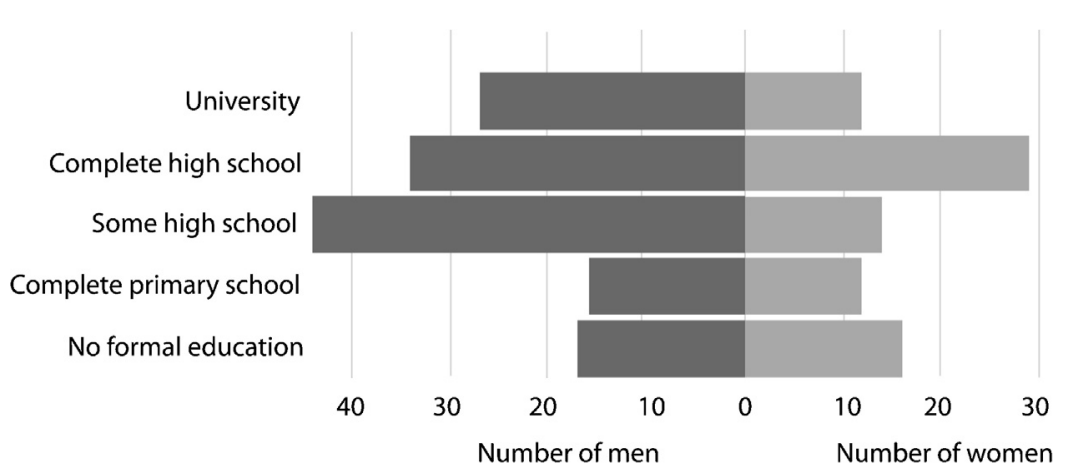

Fig. 3. Level of education of sample.

\section{Completely in favor}

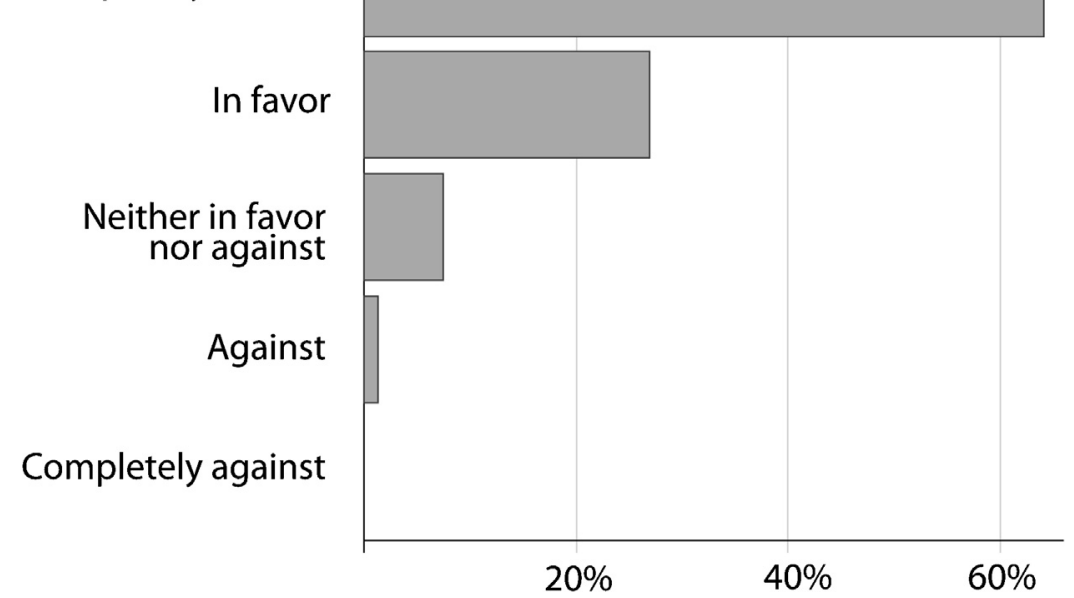

Fig. 4. Acceptance of the Noor I CSP plant (dependent variable).

Since the ground-breaking ceremony for the Noor I power plant, the general awareness of the project can be considered almost universal, this is why the perceived level of information is important for providing additional detail about questions of acceptance. Level of information was reported on a 5-point scale, 1 indicating very well informed and 5 not at all informed. Compared to the broad acceptance of the CSP project, the level of information was low, with less than $25 \%$ of respondents feeling well or at least somewhat informed and $45 \%$ feeling badly or not at all informed (see also Fig. 9). This is in line with findings by Germanwatch and Wuppertal Institute [38]. Most people receive information about the
CSP plant from family and friends ( $\sim 7 \%$, Fig. 5$)$. This reflects the importance of social networks and norms, which is supported in the World Value Survey where Moroccans prioritize family and religion considerably over politics (World Value Survey 2010-2012). The second most important source of information are mass media ( $\sim 40 \%)$, whereas all other potential sources were much less relevant, for example only $4.5 \%$ report that they receive information from public authorities and $2 \%$ received information from the Noor I project developers. Correspondingly respondents wished for more information from developers as well as from mass media. At the same time local authorities and the third sector seem to have been 


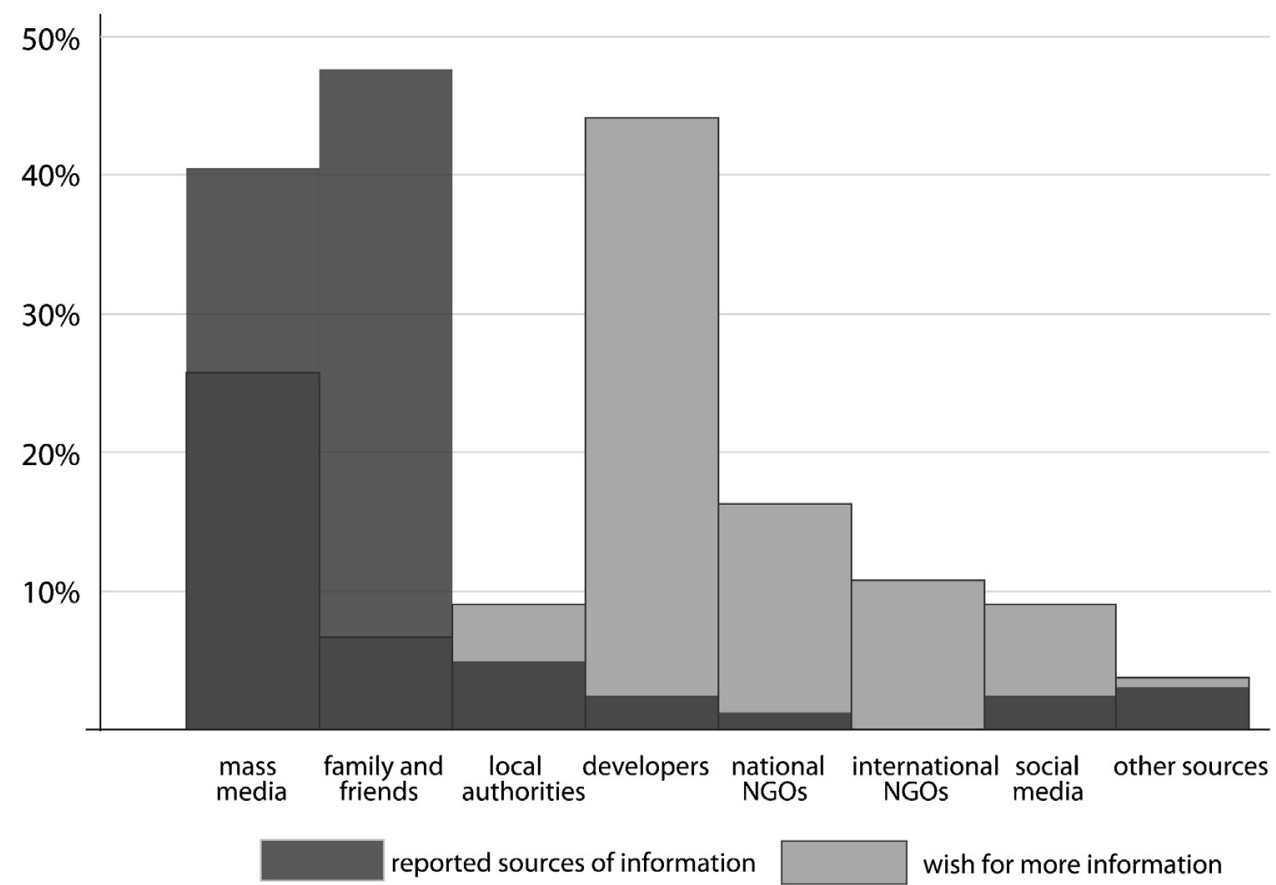

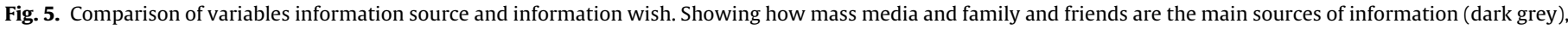
whereas people wish (light grey) for additional information from developers as well as NGOs.

much less relevant in providing information, which highlights the key role of the national actor MASEN, whom we found that respondents understood to be "developers".

Perceived fairness or procedural justice, as included in our theoretical model, had to be excluded from the analysis as the question suffered from an interpretation mistake: the question "Have you been involved in the planning and development process of the CSP plant?" was interpreted as "Would you like to work at the power plant?" We were able to identify this only through the follow-up question "How would you like to be involved?", which respondents answered by describing the kind of job they would like or why due to their profession they were not suited to work at the power plant. This revealed that more than half of our respondents (54\%) would like to work at the Noor I power plant. This misinterpretation is an interesting finding in itself as it indicates a different overall attitude towards community participation and involvement. It reflects that participatory processes are not standard procedure and awareness of such options among the general public is probably low.

Information on trust was collected using a four-point scale with 1 indicating complete trust and 4 indicating no trust. Insight is limited here as we were not cleared to ask for trust in public authorities explicitly, although developers are generally understood to be public contractor (MASEN). Trust in developers is comparably high, with almost $70 \%$ having complete or some trust (Fig. 6), which supports the qualitative findings by Germanwatch and Wuppertal Institute that the community level work of MASEN was largely successful. However, $35 \%$ of respondents answered the question on how much they trust in developers with "don't know", which means only 151 answered the question. We found no association for trust in developers and acceptance of Noor I. However, we were able to establish a statistically significant association between the dependent variable and trust in international investors (Pearson's chi2 $=10.25, p=0.017$ ). Thus trust in international investors with $60 \%$ having complete or some trust (Fig. 6) is positively linked to public acceptance, at the same time other international bodies were awarded much less trust, with $38 \%$ and $32 \%$ respectively. We therefore included trust in investors as the only independent vari- able in the regression analysis, whereas we did not include trust in developers.

We included overall expected positive and negative socioeconomic impacts on the community and on the individual level, as well as specific impacts such as job availability $(\mu=1.9)$, personal income $(\mu=2.2)$, and electricity prices $(\mu=2.3)$. Answers were obtained on five-point scales, where 1 equaled very positive impacts and 5 equaled very negative impacts.

Respondents expected socio-economic impacts to be largely positive more so for the community, $80 \%$ expect very or somewhat positive impacts, than for themselves, $66 \%$ expect a very or somewhat positive impact. Answers have to be taken with care also here, where, given the early construction stage of the power plant hopes were high for more jobs (particularly for the youth) and lower electricity prices. This was revealed by open-ended questions for the primary benefit of the project. The answers to key socio-economic impacts were positively associated with each other (Table 1). Therefore we included only impact on self in the regression model to represent socio-economic impacts overall and avoid multi-collinearity issues in the model (Fig. 7). Furthermore, this is the variable closest to our model assumptions.

$92 \%$ of respondents expected either positive or no impacts on the environment (Fig. 8). Open-ended context questions about primary benefits and harms revealed that this is because solar power is considered to be fundamentally good compared to traditional fuel sources. Only with respect to water availability over $40 \%$ of

Table 1

Spearman's rho and significance levels for socio-economic impact variables.

\begin{tabular}{llllll}
\hline & Self & Community & Income & Jobs & Electricity prices \\
\hline Self & 1.0000 & & & & \\
Community & $0.33^{* * *}$ & 1.0000 & & & \\
Income & $0.26^{* * *}$ & $0.32^{* * *}$ & 1.0000 & & \\
Jobs & $0.32^{* * *}$ & $0.20^{* * *}$ & $0.46^{* * *}$ & 1.0000 & \\
Electricity prices & 0.07 & $0.21^{* * *}$ & $0.23^{* * *}$ & $0.35^{* * *}$ & 1.0000
\end{tabular}

${ }^{* *} p<0.05$

$p<0.01$ 


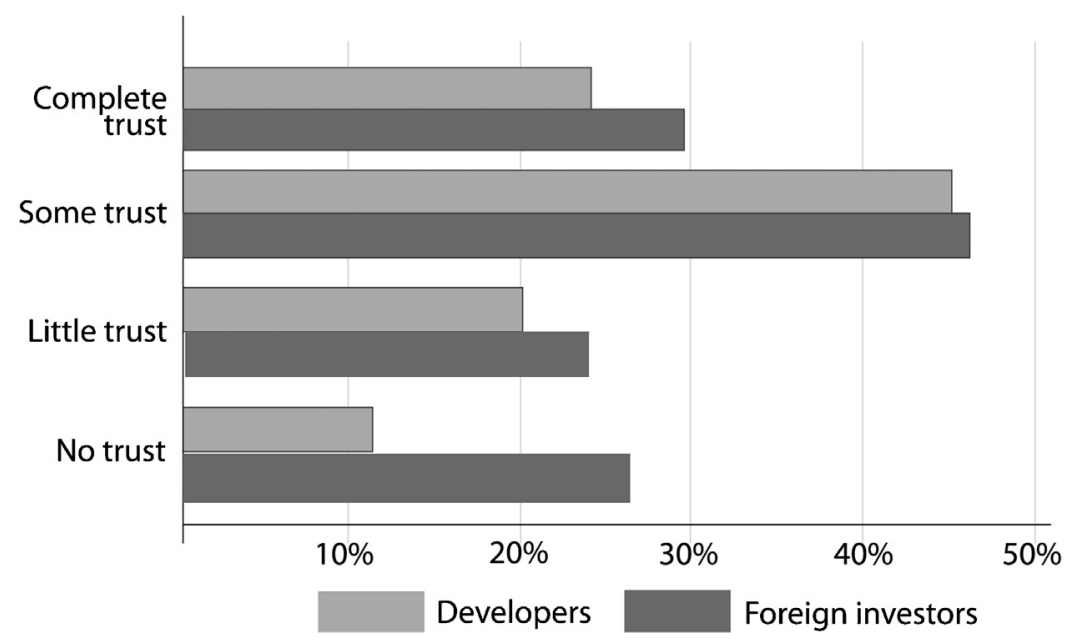

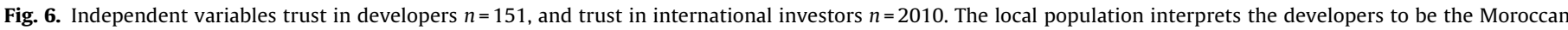
Agency for Renewable Energy (MASEN), although they are officially the contractor, not the developer.

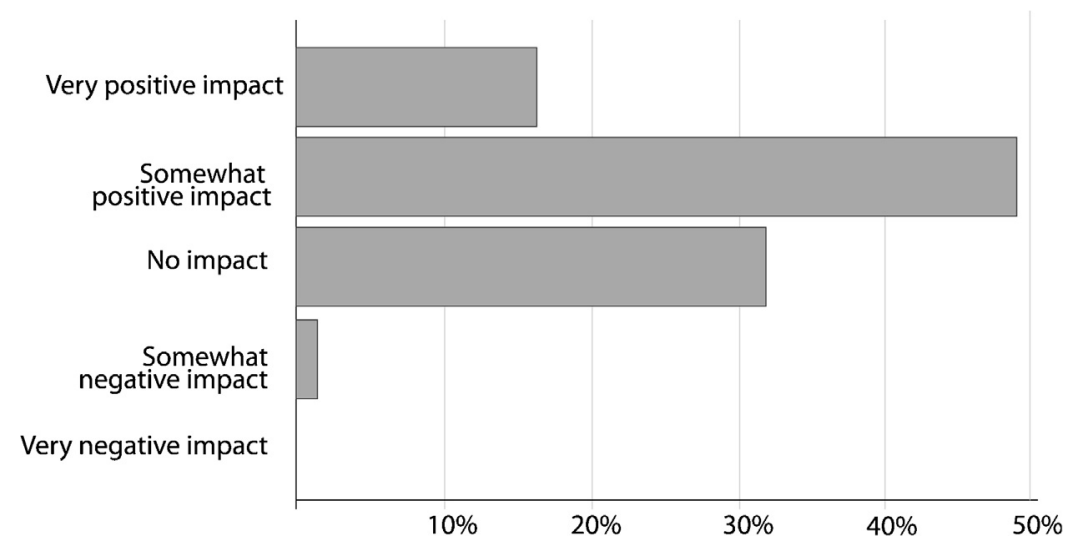

Fig. 7. Independent variable perceived impact on self.

respondents expected negative impacts. We find this still low considering the water stress in the region. This negative tendency for water-specific impacts seems however not reflected in the overall positive attitude towards the CSP plant.

Finally, almost $80 \%$ of respondents expect socio-economic benefits to be distributed unequally so that the rich will benefit more than the poor, and people somewhere else in Morocco and outside Morocco will benefit more than the local population.

\subsection{Drivers of community acceptance}

We designed the dependent variable to be ordinal, however, due to its extreme skewedness and the small numbers of negative observations in terms of attitude, we had to recode the ordinal variable into a binary one, where the value 1 corresponds to being completely in favor, and the value 0 includes all categories that range from being less enthusiastically in favor to being against. With this binary dependent variable we were able to use a logistic regression. In our baseline model we included six variables based on our theoretical model excluding procedural justice. In the second model, we replaced the single variable associated with the perceived level of information with a new set of variables that include the interaction of gender and information.

Running the logistic regression (Table 2 ) with the original variables as introduced above (excluding participatory justice) we receive a significant model $(p<0.000)$, however with low explanatory power (McFadden's $R^{2} 0.11$ ). Only two of our independent variables show a significant impact on the level of community acceptance. We find that both, a higher level of information and the environmentally-friendly image of the power plant are positively associated with community acceptance. The second model increases the explanatory power by including a relevant interaction effect. While acceptance is positively associated with the level of information overall, we find that particularly women are more enthusiastic about the project the less they are informed about it. These findings are robust to adaptations of the model, such as adding or taking out variables and changes in the type regression model. Due to the small sample size we assume however that minor associations will remain undetected, while the associations found are likely to be understated.

We explain the fact that some of the key drivers of our theoretical model, such as socio-economic impacts, and distributive justice are not reflected in the regression, with the missing link between the general enthusiasm about the project and actual knowledge, which indicates remaining uncertainties in people's expectations and thus variables do not align. Moreover, the independent variables distributive justice and impact on water availability indicate a more critical stance vis a vis Noor I in contrast to the enthusiasm shown for the project also suggests that the positive attitude is not one that people made up based on all of their own expectations.

About half of the respondents felt badly or not at all informed. This is reflected in the interaction effect included in our model, where there is an association between women who perceive themselves to be badly informed and are very much in favor of the 


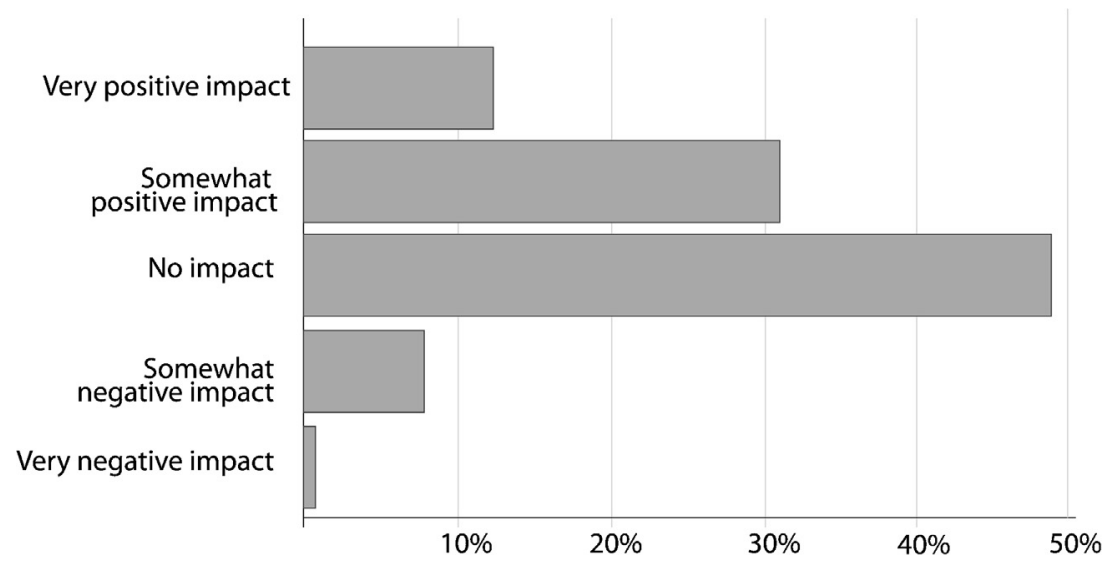

Fig. 8. Independent variable perceived impact on the environment.

Table 2

Logistic regression of drivers of community acceptance.

\begin{tabular}{|c|c|c|}
\hline & $\begin{array}{l}\text { (1) } \\
\text { Original model } \\
\text { as intended }\end{array}$ & $\begin{array}{l}\text { (2) } \\
\text { Including interaction } \\
\text { (level of information } \\
\text { and gender) }\end{array}$ \\
\hline \multicolumn{3}{|l|}{ Acceptance } \\
\hline $\begin{array}{l}\text { Perceived level of } \\
\text { information }\end{array}$ & $\begin{array}{l}1.66^{* *} \\
(3.28)\end{array}$ & \\
\hline Expected impact on self & $\begin{array}{l}0.78 \\
(-1.09)\end{array}$ & $\begin{array}{l}0.86 \\
(-0.66)\end{array}$ \\
\hline $\begin{array}{l}\text { Expected impact on the } \\
\text { environment }\end{array}$ & $\begin{array}{l}2.20^{* * *} \\
(3.68)\end{array}$ & $\begin{array}{l}2.39^{* * *} \\
(3.74)\end{array}$ \\
\hline \multirow[t]{2}{*}{$\begin{array}{l}\text { Distributive justice } \\
\text { (equal vs. non-equal } \\
\text { distribution) }\end{array}$} & 0.90 & 0.81 \\
\hline & $(-0.28)$ & $(-0.49)$ \\
\hline $\begin{array}{l}\text { Trust in international } \\
\text { institutions }\end{array}$ & $\begin{array}{l}1.05 \\
(0.28)\end{array}$ & $\begin{array}{l}1.09 \\
(0.46)\end{array}$ \\
\hline $\begin{array}{l}\text { Distance from Noor I } \\
\text { project site }\end{array}$ & $\begin{array}{l}1.25 \\
(1.07)\end{array}$ & $\begin{array}{l}1.17 \\
(0.69)\end{array}$ \\
\hline Gender (female vs. male) & & $\begin{array}{l}2.73 \\
(1.14)\end{array}$ \\
\hline Badly informed \# female & & $\begin{array}{l}0.09^{*} \\
(-2.35)\end{array}$ \\
\hline LR chi2 & 29.78 & 41.95 \\
\hline Prob $>$ chi 2 & 0.000 & 0.0001 \\
\hline Pseudo $R^{2}$ (McFadden's) & 0.11 & 0.16 \\
\hline Observations & 211 & 207 \\
\hline
\end{tabular}

Exponentiated coefficients (odds ratios); $z$ statistics in parentheses.

${ }^{*} p<0.05$.

** $p<0.01$.

*** $p<0.001$

project. Indeed, the level of information varies strongly across gender, a Kruskal-Wallis test yields a probability of 0.0012 that that this is in fact true.

It seems indeed that an equal percentage of men and women feel "very well informed" (7\%), "neither well nor badly" (around 20\%) and "badly informed" (around 40\%), while the big difference lies in women feeling more often "not at all informed" $(27 \%)$ and rarely "somewhat informed" (10\%, Fig. 9). Other variables were similar. The impact variables such as electricity prices and water reflect a more skeptical stance in the population than could account for the enthusiastic acceptance of the CSP plant.

Beyond gender we controlled for demographic and socioeconomic variables, such as age, education, and employment status. Although basic patterns, such as between age and education, confirmed that our data was indeed reflecting a realistic picture of the population, these variables could not account for any changes in public acceptance.

\section{Discussion}

We investigated the CSP flagship project Noor I in Morocco and found that there is practically no opposition to the project. Members of our survey sample, representative for the region of Ouarzazate, seemed to be overwhelmingly in favor of the project: $91 \%$ being completely in favor or in favor. This high level of community acceptance is largely driven by expectations of positive or at least no negative environmental impacts. Additional open-ended questions reveal that CSP is considered to be good, as it uses the renewable source of the sun and does not pollute the environment such as fossil fuels. At the same time that acceptance is high, however, the population in the area felt insufficiently informed: $45 \%$ of respondents being badly or not at all informed. Women in particular felt that they were poorly informed. While one might expect the poorly informed to be skeptical of the solar project, we found the opposite to be the case: the less informed people were, the more broadly positive they felt.

This is an interesting finding, as it suggests that too much information early on in the project might lead to stronger opposition. Taken out of context this could be interpreted by developers that it is helpful to keep information away from the population. The existing literature, largely based on case studies in Europe and North America, would suggest this to be a risky strategy, as it might lead to unpleasant surprises and even more heated opposition in the future, if negative impacts were to occur. We were not able to find out whether participation in the planning process was important to the population, but rather found that this is something that so far has been beyond consideration of the general public, despite participatory processes for key stakeholders. At the same time, respondents voiced a clear wish for more information from the state-owned renewable energy agency MASEN. This indicated that people are not content with their current level of information. One can speculate, based on this finding, that if information continues to be sparse, and any negative outcomes of the project are perceived, support might begin to falter.

The literature suggests that public acceptance is often linked to positive expectations for socio-economic improvement, particularly in a case such as our where the area around the CSP plant is economically disadvantaged. We did not observe this to be the case. However, all our data on socio-economic impacts indicated positive expectations, more for the community - 75\% expect very or somewhat positive socio-economic impacts - than personally, particularly when it comes to jobs and electricity prices. Moreover, open-ended questions showed how job creation is people's primary concern for the region.

Our data lead us to believe that the universally high acceptance might partly result from people telling us what they thought we 


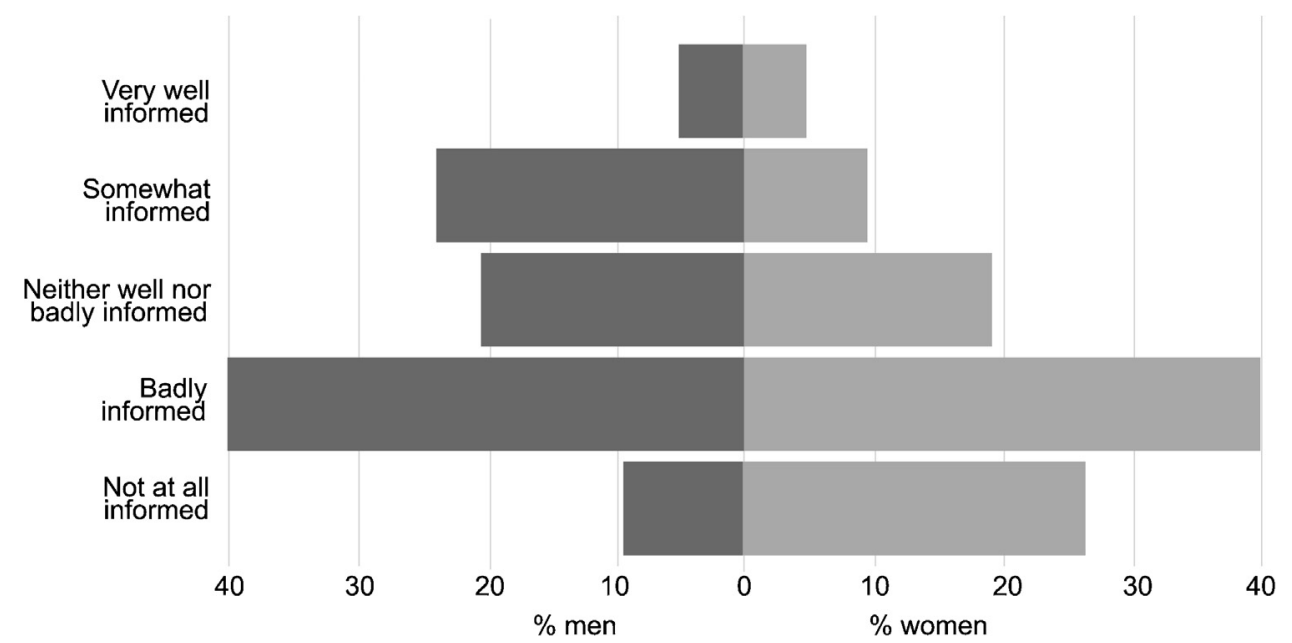

Fig. 9. Perceived level of information by gender.

wanted to hear. Apart from the expectations for economic value creation, we find that despite the high level of awareness and acceptance people do expect economic impacts to be distributed unequally, and while overall environmental impacts are not perceived to be negative, water availability as a separate issue is seen much more critically and potentially negatively. Finally, the low perceived low level of information points towards a disparity between the overwhelmingly high support reported and actual concerns that might remain or are unknown. We believe the bias to be one of social desirability, which may have been introduced by one or all three of the following reasons: (1) the fact that the interviews were conducted face to face; (2) the fact that the project developers had conducted local campaigns; and (3) the fact that King Muhammad IV had been present at the ground-breaking ceremony.

Despite this potential bias, which might explain the extreme skewedness of the results, we believe that public acceptance is still overall positive, standing somewhat in contrast to studies that have been carried out in Europe or North America. This is generally good news for the implementation of large-scale renewables in the region as such factors as aesthetic disruption of the landscape, opaque planning processes and NIMBY seem not to be a problem. Yet, those responsible will be well advised to consider the wish for more information and the currently high expectations regarding job creation and electricity prices, so as to avoid disappointing the local population in the future.

While this study provides an important body of information, it is subject of several limitations. Apart from limited financial and time resources, translating the questionnaire into Arabic, with guidance for adaptation to Berber is one step in the research process which reduces precision of the questionnaire, more difficult yet is the communication about certain concepts used for our model of acceptance, most notably, but not exclusively, ideas of public participation.

The fact that Noor I has been in the early construction phase during the fieldwork for this study is both an advantage and a disadvantage. Public awareness and acceptance is of course most important and effective during the planning and early construction phase of an infrastructure project, whereas once the power plant is running, it is much more difficult to influence. Yet, at the same time many of the expected impacts may be confused with high hopes, whereas actual impacts will only become visible once Noor I has been fully operational for a while.

The study at hand has to be an individual case study as Noor I is a unique project in the MENA region, shadowing all other attempts in terms of its size. Noor I will not only be a benchmark for further projects in the region but it has potentials to be a driver for further the entire CSP industry development in the region. Currently no second project of similar meaning and importance exists in the region.

At the same time we believe that public acceptance issues while being particular to certain projects in some ways, reflect underlying belief and value systems that are shared across countries, and regions as they are rooted in their similar cultural, religious and political traditions. We thus believe that our model of public acceptance can be further developed based on the insights from this case, and that it is indicative for similar projects in other MENA countries. Moreover it may serve as a stepping stone for further acceptance studies in the region. These will become increasingly relevant as local opposition to power installations and resulting problems for developers have shown in other cases in the region [38].

\section{Acknowledgments}

The work described in this paper was supported by the European Research Council in frames of its "ERC StG2012 - 313553" grant. The paper reflects the authors' views and not those of the European Research Council. We wish to thank all our colleagues who provided professional advice and collaboration. We are especially grateful to Ghizlan Atik, Souaad Ouarzim, Fatima Ahouli, Zakariya Ait El Bouhali, Mohammed Boulaid, Mohammed Ait El Haj and Christof Kögler. The paper benefited from constructive criticism by the faculty and participants of the Oikos Young Scholars Energy Academy.

\section{References}

[1] 5 Capitals Environmental \& Management Consulting, Quarzazate Solar Power Complex, Phase 1 Morocco, Specific Environmental and Social Impact Assessment, vols. 1-3, Rabat, 2012.

[2] AfDB (African Development Bank Group), Summary of the Environmental and Social Impact Assessment, Tunis, 2011.

[3] A. Ahmad, M. Rashid, N.A. Omar, S.S. Alam, Perceptions on renewable energy use in Malaysia: mediating role of attitude, J. Pengurusan 41 (2014)

[4] S. Batel, P. Devine-Wright, T. Tangeland, Social acceptance of low carbon energy and associated infrastructures: a critical discussion, Energy Policy 58 (2013) 1-5, http://dx.doi.org/10.1016/j.enpol.2013.03.018.

[5] A. Battaglini, N. Komendantova, P. Brtnik, A. Patt, Perception of barriers for expansion of electricity grids in the European Union, Energy Policy 47 (2012) 254-259, http://dx.doi.org/10.1016/j.enpol.2012.04.065.

[6] Battaglini, Antonella, Johan Lilliestam, Armin Haas, A.G. Patt, Development of SuperSmart Grids for a more efficient utilization of electricity from renewable resources, J. Clean. Prod. 17 (2009) 911-918. 
[7] B. Brand, A.B. Stambouli, D. Zejli, The value of dispatchability of CSP plants in the electricity systems of Morocco and Algeria, Energy Policy 47 (2012) 321-331.

[8] K. Burningham, Using the language of NIMBY: a topic for research, not an activity for researchers, Local Environ. 5 (2000) 55-67, http://dx.doi.org/10. 1080/135498300113264.

[9] J.E. Carlisle, S.L. Kane, D. Solan, J.C. Joe, Support for solar energy: examining sense of place and utility-scale development in California, Energy Res. Soc. Sci. 3 (2014) 124-130, http://dx.doi.org/10.1016/j.erss.2014.07.006.

[10] J.J. Cohen, J. Reichl, M. Schmidthaler, Re-focussing research efforts on the public acceptance of energy infrastructure: a critical review, Energy (2014), http://dx.doi.org/10.1016/j.energy.2013.12.056.

[11] R. Cowell, G. Bristow, M. Munday, Acceptance, acceptability and environmental justice: the role of community benefits in wind energy development, J. Environ. Plan. Manage. 54 (2011) 539-557, http://dx.doi.org 10.1080/09640568.2010.521047.

[12] P. Devine-Wright, Beyond NIMBYism: towards an integrated framework for understanding public perceptions of wind energy, Wind Energy 8 (2005) 125-139, http://dx.doi.org/10.1002/we.124.

[13] J.M. Eder, C.F. Mutsaerts, P. Sriwannawit, Mini-grids and renewable energy in rural Africa: how diffusion theory explains adoption of electricity in Uganda, Energy Res. Soc. Sci. 5 (2015) 45-54, http://dx.doi.org/10.1016/j.erss.2014.12 014.

[14] S. Erdle, The DESERTEC Initiative. Owering the development perspectives of Southern Mediterranean countries? German Development Institute, 2010.

[15] J. Firestone, W. Kempton, M.B. Lilley, K. Samoteskul, Public acceptance of offshore wind power: does perceived fairness of process matter? J. Environ. Plan. Manage. 55 (2012) 1387-1402, http://dx.doi.org/10.1080/09640568. 2012.688658.

[16] K. Fritzsche, D. Zejli, D. Tanzler, The relevance of global energy governance for Arab countries: the case of Morocco, Energy Policy 39 (2011) 4497-4506.

[17] C. Haggett, Over the sea and far away? A consideration of the planning politics and public perception of offshore wind farms, J. Environ. Policy Plan. 10 (2008) 289-306, http://dx.doi.org/10.1080/15239080802242787.

[18] R. Horbaty, S. Huber, G. Ellis, Large-scale wind deployment, social acceptance, Wiley Interdiscip. Rev.: Energy Environ. 1 (2012) 194-205, http://dx.doi.org/ 10.1002/wene.9.

[19] N.M.A. Huijts, C.J.H. Midden, A.L. Meijnders, Social acceptance of carbon dioxide storage, Energy Policy 35 (2007) 2780-2789, http://dx.doi.org/10. 1016/j.enpol.2006.12.007.

[20] A. Jobert, P. Laborgne, S. Mimler, Local acceptance of wind energy: factors of success identified in French and German case studies, Energy Policy 35 (2007) 2751-2760, http://dx.doi.org/10.1016/j.enpol.2006.12.005.

[21] J. Lilliestam, J. Bielicki, A.G. Patt, Comparing carbon capture and storage (CCS) with concentrating solar power (CSP): potentials, costs, risks, and barriers, Energy Policy 47 (2012) 447-455.

[22] MASEN, Environmental Impact Assessment of the development plan of the site of the Ouarzazate Solar Compound, Non technical summary, 2012.

[23] C. Oltra, R. Sala, R. Solà, M. Di Masso, G. Rowe, Lay perceptions of carbon capture and storage technology, Int. J. Greenh. Gas Control 4 (2010) 698-706, http://dx.doi.org/10.1016/j.ijggc.2010.02.001.

[24] M.A. Petrova, NIMBYism revisited: public acceptance of wind energy in the United States, Wiley Interdiscip. Rev.: Clim. Change 4 (2013) 575-601, http:/ dx.doi.org/10.1002/wcc. 250 .

[25] Stefan Pfenninger, Paul Gauche, Johan Lilliestam, Kerstin Damerau, Fabian Wagner, Anthony Patt, Potential for concentrating solar power to provide baseload and dispatchable power, Nat. Clim. Change 4 (8) (2014) 689-692.

[26] R. Pitz-Paal, A. Amin, M. Bettzuge, P. Eames, G. Flamant, F. Fabrizi, J. Holmes, A Kribus, H. van der Lann, A. Lopez, F. Novo, P. Papagiannakopoulos, E. Pihl, A. Smith, H. Wagner, Concentrating solar power in Europe, the Middle East and North Africa: a review of development issues and potential to 2050, J. Sol. Energy Eng. 134 (2) (2012), Technical brief.

[27] T. Pregger, E. Lavagno, M. Labriet, P. Seljom, M. Biberacher, M. Blesl, F. Trieb, et al., Resources, capacities and corridors for energy imports to Europe, Int. J. Energy Sect. Manage. 5 (1) (2011) 125-156.
[28] J.C. Rogers, E.A. Simmons, I. Convery, A. Weatherall, Public perceptions of opportunities for community-based renewable energy projects, Energy Policy 36 (2008) 4217-4226, http://dx.doi.org/10.1016/j.enpol.2008.07.028.

[29] G. Schellekens, A. Battaglini, J. Lillestam, J. McDonnell, A.G. Patt, 100\% Renewable Electricity. A Roadmap to 2050 for Europe and North Africa, PricewaterhouseCoopers, London, 2010.

[30] B. Schinke, Civil society perspectives on renewable energy policy making in Morocco, 2015.

[31] P. Slovic, Perceived risk, trust, and democracy, Risk Anal. 13 (1993) 675-682, http://dx.doi.org/10.1111/j.1539-6924.1993.tb01329.x.

[32] B.K. Sovacool, P. Lakshmi Ratan, Conceptualizing the acceptance of wind and solar electricity, Renew. Sustain. Energy Rev. 16 (2012) 5268-5279, http://dx. doi.org/10.1016/j.rser.2012.04.048.

[33] F. Trieb, H. Mueller-Steinhagen, J. Kern, Financing concentrating solar power in the Middle East and North Africa-subsidy or investment? Energy Policy 39 (January (1)) (2011) 307-317

[34] Peter Viebahn, Yolanda Lechon, Franz Trieb, The potential role of concentrated solar power (CSP) in Africa and Europe-a dynamic assessment of technology development, cost development and life cycle inventories until 2050, Energy Policy 39 (8) (2011) 4420-4430, http://dx.doi.org/10.1016/j. enpol.2010.09.026.

[35] M. Wolsink, Wind power and the NIMBY-myth: institutional capacity and the limited significance of public support, Renew. Energy 21 (2000) 49-64, http:// dx.doi.org/10.1016/S0960-1481(99) 00130-5.

[36] M. Wolsink, Wind power implementation: the nature of public attitudes: equity and fairness instead of backyard motives, Renew. Sustain. Energy Rev. 11 (2007) 1188-1207, http://dx.doi.org/10.1016/j.rser.2005.10.005.

[37] M. Wolsink, Undesired reinforcement of harmful self-evident truth concerning the implementation of wind power, Energy Policy 48 (2012) 83-87.

[38] Wuppertal Institute, Germanwatch, Social CSP-energy and development: exploring the local livelihood dimension of the Noor II CSP project in Southern Morocco, Final Report to the German Federal Ministry for Economic Cooperation and Development (BMZ), Wuppertal Institute for Climate, Environment and Energy Wuppertal, Germanwatch, Bonn, 2015.

[39] R. Wüstenhagen, M. Wolsink, M.J. Bürer, Social acceptance of renewable energy innovation: an introduction to the concept, Energy Policy 35 (2007) 2683-2691, http://dx.doi.org/10.1016/j.enpol.2006.12.001.

[40] M. Yazdanpanah, N. Komendantova, R.S. Ardestani, Governance of energy transition in Iran: investigating public acceptance and willingness to use renewable energy sources through socio-psychological model, Renew. Sustain. Energy Rev. 45 (2015) 565-573, http://dx.doi.org/10.1016/j.rser. 2015.02.002.

[41] X. Yuan, J. Zuo, D. Huisingh, Social acceptance of wind power: a case study of Shandong Province, China, J. Clean. Prod. (2015), http://dx.doi.org/10.1016/j. jclepro.2014.12.097.

[42] P. Zhai, E.D. Williams, Analyzing consumer acceptance of photovoltaics (PV) using fuzzy logic model, Renew. Energy 41 (2012) 350-357, http://dx.doi.org 10.1016/j.renene.2011.11.041.

[43] J. Zöllner, P. Schweizer-Ries, C. Wemheuer, Public acceptance of renewable energies: results from case studies in Germany, Energy Policy 36 (2008) 4136-4141, http://dx.doi.org/10.1016/j.enpol.2008.06.026.

[44] A. Zyadin, A. Puhakka, P. Ahponen, T. Cronberg, P. Pelkonen, School students knowledge, perceptions, and attitudes toward renewable energy in Jordan, Renew. Energy 45 (2012) 78-85, http://dx.doi.org/10.1016/j.renene.2012.02 002.

[45] C. Gross, Community perspectives of wind energy in Australia: the application of a justice and community fairness framework to increase social acceptance, Energy Policy 35 (2007) 2727-2736, http://dx.doi.org/10.1016/j.enpol.2006. 12.013.

[46] Y. Guo, P. Ru, J. Su, L.D. Anadon, Not in my backyard, but not far away from me: local acceptance of wind power in China, Energy 82 (2015) 722-733, http://dx.doi.org/10.1016/j.energy.2015.01.082.

[47] N. Gupta, A.R.H. Fischer, L.J. Frewer, Socio-psychological determinants of public acceptance of technologies: a review, Public Underst. Sci. 21 (2012) 782-795, http://dx.doi.org/10.1177/0963662510392485. 